\title{
LA LÓGICA DE LOS PROBLEMAS HUMANOS
}

Sumarıo: 1. La dialéctica, tópica y retórica en la Antigüedad Clásica. 2. Algunas consideraciones sobre la dialéctica y tópica. 3. Pensamiento problemático, dialéctica y tópica en la Antigüedad Cristiana y en la Edad Media. 4. Eclipse de la dialéctica por obra del espiritu cartesiano, y reivindicación de ella por Vico. 5. Demoledoras criticas en el siglo xix y en el $x x$ contra el empleo de la lógica tradicional deductiva en la Jurisprudencia, y en la vida humana en general. 6. Ensayo de un nuevo planteamiento de la cuestión sobre la lógica de los problemas humanos.

\section{La dialéctica, tópica y retórica en la Antigüedad Clásica}

Se trata de un viejo tema; pero con acentos de relativa novedad, o, mejor dicho, con el propósito de una renovación -eadem sed aliter-, que aproveche la experiencia de muchos siglos de meditación filosófica, y con el intento de reactualizar, a la altura del pensamiento de nuestra época, la añeja cuestión sobre el razonamiento aplicado a los problemas humanos: los morales, los políticos, los jurídicos, los económicos, etcétera.

Los orígenes de este tema se remontan a la Antigüedad griega, y también a la latina. Las cuestiones relativas a los razonamientos para decidir los problemas prácticos, que conciernen a la conducta humana, constituyen uno de los puntos centrales en los desarrollos de los sofistas, probablemente el punto de mayor importancia, sobre todo de mayor consistencia, y también de mayor alcance, en las elaboraciones de aquellos maestros de retórica. Aparte de lo mucho que haya de travesura y pirueta intelectuales en el pensamiento de los sofistas, aparte de las dimensiones deleznables y peyorativas que caractericen a éste, sin embargo, en él se halla presente un tema de enorme calibre y de largo alcance: el tema de la argumentación, del razonamiento, que se encamina a tratar problemas prácticos de la vida humana, y de hallar para éstos la solución más adecuada.

A la mala fama que los sofistas adquirieron ya en su época, y sobre todo a la connotación peyorativa que ese vocablo ha venido arrastrando, contribuyó decisivamente el hecho de que muchos de aquéllos tendiesen a orientarse sólo hacia el arte de la contienda y la disputa, hacia el arte de "hacer más fuertes los discursos débiles", merced a cualquier medio, es decir, hacia el arte, no de convencer al adversario o a quien debían vencer, sino de reducir a éste al silencio. Así, no pocas de las actuaciones de los sofistas cultivaron el virtuosismo de la contienda, y desembocaron en actitudes unas veces nihilistas, otras veces cínicas. 1

1 Véase H. Gomperz, Sophistik und Rethorik, 1912; G. Kafka, Die Vorsocratiker, Munich, 1921; Alois Fischer, "La filosofía presocrática", en Los grandes pensadores, Espasa- 
Pero, independientemente de aquellos abusos y vicios, lo cierto es que los sofistas enfocaron principalmente los problemas de la conducta humana práctica, especialmente los relativos a la moral, al Estado, al Derecho, y a la sociedad. Cierto que en no pocas ocasiones algunos de los sofistas se dejaron llevar por prejuicios, unas veces - por ejemplo, propincuidad a una tiranía aristocrática- y por intereses, otras veces. Así, por ejemplo, Calicles y Trasímaco. Pero otros, como Antifón, por el contrario, acentuaron vigorosamente la igualdad de todos los hombres, tanto de los helenos como de los extranjeros.

En todo caso, sin embargo, en contraste con las otras direcciones filosóficas presocráticas, las cuales habían enfocado sobre todo los problemas de la especulación sobre la naturaleza, sobre el ser, sobre Dios, los sofistas colocaron en el centro de su preocupación los temas humanos propiamente dichos. Y, en fin de cuentas, el pensamiento de Sócrates se originó sobre todo por esa preocupación, elevando el tema de lo humano a un tratamiento honesto, rigoroso y noble.

Magistralmente, Eduardo García Máynez ${ }^{2}$ ha hecho patente y ha destacado importantes contribuciones de los sofistas a algunas tesis básicas de Derecho Natural: unas orientadas en un sentido democrático (tal y como aparece en las ideas que inspiraron el Discurso en loor de los muertos de la guerra atribuido a Pericles); otras, de tendencia conservadora (Protágoras), otras, de tono revolucionario (Calicles).

Las actividades y las enseñanzas de los sofistas fueron englobadas bajo la denominación de "retórica", en tanto que se encaminaban a desenvolver y cultivar el arte de la persuasión, especialmente para las discusiones políticas y las controversias jurídicas. Pero junto a esa denominación de "retórica", se va también abriendo paso en el pensamiento griego otro nombre, el de "dialéctica", término mucho más adecuado, $\mathrm{y}$, sobre todo, más expresivo.

Claro que ni qué decir tiene que la palabra dialéctica referida al pensamiento de la Antigüedad grecorromana, así como también a muchas nuevas elaboraciones producidas de los dos últimos decenios del siglo $\mathrm{xx}$, no tiene ninguna conexión con el sentido de esta palabra en la filosofía de Hegel, ni en la concepción de Marx. Es más, podría atinadamente decirse que la dialéctica hegeliana y la marxista son esencialmente antidialécticas desde el punto de vista de Sócrates, Platón, Aristóteles, Cicerón, por lo que respecta a la Antigüedad Clásica, y de Viehweg y Perelman, como ejemplos del siglo $\mathbf{x x}$.

Calpe Argentina, Buenos Aires-México, 1938; Carl Prantl, Geschichte der Logik im Abendlande, tomo I, 1855 .

¿2 Véase Eduardo Garcia Máynez, "El Derecho natural en la época de Sócrates", en Ensayos filosófico-juridicos, Universidad Veracruzana, Xalapa, México, 1959. Véase también: Juan Llambías de Azevedo, El pensamiento del Derecho y del Estado en la Antigüedad: desde Homeros a Platón, Librería Jurídica, Bucnos Aires, 1956. 
Originariamente la palabra "dialéctica" significa discurso o intercambio entre dos o más oradores, que respectivamente expresan dos o más posiciones u opiniones. ${ }^{3}$ Esta concepción de un pensar interpersonal, de un pensar basado en el choque, oposición o paradoja, aparece embebido en el mismo término: diá y légein. Pero ese mismo sentido aparece reiterado en las primeras etapas de la historia de ese método. Se dice que Aristóteles atribuyó la invención de la dialéctica a Zenón de Elea, quien defendió la posición de Parménides, desenvolviendo las contradicciones en las cuales se halla implícita la posición opuesta. 4 Jenofonte atribuye a Sócrates una definición de la discusión dialéctica, la cual destaca la relación entre el "clasificar" (dialégein) y el "discutir" (dialégesthai). Se llama discusión, por virtud de la práctica de reunirse para deliberar en común.

Sin embargo, en esas primeras etapas de la dialéctica, ésta se presenta con diversas significaciones, incluso contradictorias. A veces, cual sucede con Platón, ${ }^{5}$ el diálogo o discusión es la vía para una elaboración científica o filosófica. Otras veces, en cambio, por dialéctica se entiende no el tratamiento científico o filosófico de un problema, sino más bien, la ponderación de opiniones diferentes. En el primer caso se aplica la palabra dialéctica, cuando el estudio y el análisis rigoroso de un tema científico o filosófico se desenvuelve en la forma de un diálogo o conversación, que se encamina al esclarecimiento de ese tema, y a la clasificación de las cosas, con el fin de establecer la ciencia de la realidad, sobre todo de las cosas eternas e inmutables. De esta suerte, la dialéctica define los términos, aclara las mentes, y descubre verdades sobre las cosas, a través de la discusión y del diálogo; y es el método de toda ciencia que se ocupe de la naturaleza de las cosas; es la suprema ciencia que pone los cimientos de todas las ciencias y de todas las artes. Sucede, sin embargo, que ese método del diálogo, de la conversación, de la discusión, fue empleado por Sócrates no solamente para el estudio de las verdades eternas, de la auténtica naturaleza de las cosas, sino también para el tratamiento de las controversias humanas en torno a problemas prácticos concretos.

Esta segunda acepción de la palabra dialéctica se perfila mucho mejor en Aristóteles, ${ }^{6}$ para quien la dialéctica no es el método único de la filosofía, sino que, por el contrario, es el método para tratar sobre la mayor o menor

3 Jenofonte, Memorables, IV, 5, 12. Es excelente sobre estos temas el trabajo de Richard McKeon, "Dialectic and Political Thought and Action", en Ethics: An International Journal of Social, Political and Legal Philosophy, vol. LXV, No 1, oct. 1954.

4 Véase Diógenes Laertius, Lives of Eminent Philosophers, trad. de Yonge, en Bohn's Classical Library, VIII, 57 y IX, $5,12$.

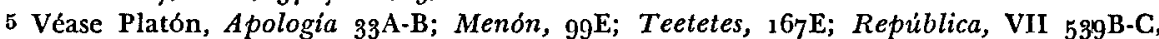
VI, $511 \mathrm{~B}-\mathrm{C}, 533 \mathrm{C}-\mathrm{D}, 534 \mathrm{~B}, 537 \mathrm{C} ;$ El sofista, $230 \mathrm{~B}-231 \mathrm{~B}, 253 \mathrm{~A}-\mathrm{D} ;$ y $259 \mathrm{C}-\mathrm{D} ;$ Fedro, $265 \mathrm{E}$ y $276 \mathrm{C} ;$ El político, $285 \mathrm{D}-287 \mathrm{C}$; Filebo ${ }_{57} \mathrm{E}-58 \mathrm{~A}$.

6 Aristóteles, Tópica, I, 1. 
probabilidad de las opiniones en materia práctica, principalmente moral, política y jurídica, en vista a hallar la solución relativamente de más prudencia. En ese segundo sentido, mucho más estricto, dialéctica no coincide con demostración científica, no coincide con razonamiento apodíctico, sino que significa esfuerzo dirigido a encontrar la solución más adecuada o prudente respecto de un problema práctico, sobre el cual se manifiestan opiniones divergentes. Propiamente, en sentido rigoroso, la demostración cientifica no es un pensar entre dos personas, no es un diálogo; por el contrario se basa sobre las causas y sobre la naturaleza de las cosas. En cambio, el pensar entre dos personas suscitado por el choque entre dos o más opiniones, se encamina a hallar el equilibrio entre tesis opuestas, a aprender las lecciones de la experiencia. Mientras que el razonamiento estrictamente científico, rigorosamente deductivo, de construcción sistemática, intenta llegar a la verdad auténtica; por el contrario, el pensamiento dialéctico arranca, no de premisas indiscutibles y evidentes, antes bien, de opiniones respetables, e intenta, ponderando cada una de ellas, darse cuenta de a cuál corresponda un mayor grado de probabilidad o de prudencia, o intentá hallar una síntesis que armonice o que lleve a cabo un compromiso aceptable y conveniente entre posiciones que parecían irreductiblemente antitéticas.

De los estudios de Aristóteles sobre lógica quedó como altísimo monumento, siempre recordado, y al que todavía se sigue recurriendo, su obra el Organon, que con alguna justificación podría considerarse como un genial tratado del pensamiento apodíctico y sistemático. Pero Aristóteles no se limitó a explorar y a hacer grandes descubrimientos en ese terreno, antes bien, se ocupó, asimismo, de otro campo diferente de la lógica, del campo de lo dialéctico, al que dedicó un serio estudio: el estudio sobre la retórica o tópica, y además múltiples análisis en otras varias de sus obras.

Según Aristóteles, la tópica no pertenece solamente a las disputas de los sofistas, sino que pertenece también al campo de lo dialéctico, en tanto que ese campo queda diferenciado de lo apodíctico. Así, Aristóteles quiere que su ciencia de la lógica abarque no sólo el sector de lo apodíctico, sino tam. bién el dominio del viejo arte de la disputa, es decir, el área de la tópica. A este respecto, dice Aristóteles que su labor apunta a encontrar un método gracias al cual podamos sacar conclusiones sobre cualquier problema práctico planteado, de tal manera que no caigamos en contradicciones. Se trata con referencia a cualquier problema práctico, de derivar conclusiones partiendo de opiniones que parezcan adecuadas.

Aristóteles acentúa que las conclusiones que se buscan y se sacan mediante la tópica, son solamente conclusiones dialécticas y no constituyen un pensamiento apodíctico. Aristóteles establece la siguiente clasificación: r) tenemos una apodictica, cuando la conclusión se obtiene partiendo de proposiciones verdaderas y primarias, o de proposiciones cuyo conocimiento a su vez 
se ha derivado de proposiciones verdaderas y primarias; 2) tenemos una conclusión dialéctica cuando ella es extraída de opiniones; 3) y una conclusión eristica o sofística es aquella que se basa sobre meras apariencias de opiniones que no lo son efectivamente; 4) finalmente, hay conclusiones erróneas, equivocadas o deficientes, desde el punto de vista de las proposiciones particulares de determinadas ciencias. ${ }^{7}$

El análisis de las conclusiones dialécticas, que son objeto de la tópica, muestra lo siguiente: tales conclusiones no se diferencian de las apodícticas desde el punto de vista formal. Tales conclusiones son correctas en su aspecto formal - lo cual desde luego no puede aplicarse a las conclusiones erísticas o sofísticas. Las conclusiones dialécticas se diferencian de las otras clases de conclusiones más bien por la indole de sus premisas. También con respecto a este punto de vista, Aristóteles clasifica las conclusiones según la índole de sus premisas. Conclusiones dialécticas son aquellas que tienen como premisas opiniones respetables, que parecen verdaderas y aceptables (endoxa). Esas opiniones, o endoxa, son aquellas proposiciones que parecen verdaderas o a todos, o a la mayoría, o a los sabios, o entre éstos a los más conocidos y respetables. La tópica estudia las conclusiones sacadas de premisas que parecen verdaderas según una opinión famosa o conspicua. ${ }^{8}$

Tiene gran importancia la observación de Aristóteles de que, mientras que el pensamiento apodíctico parte de premisas generales e indiscutibles, por el contrario, el pensamiento dialéctico, es decir, toda discusión, surge de proposiciones concretas en torno a problemas concretos.

A pesar de la diferencia entre la lógica de lo apodíctico por una parte, y la dialéctica por otra, Aristóteles reconoce que en la segunda, la dialéctica; se hace también a veces uso de la inducción y del silogismo. Para poder encontrar conclusiones adecuadas, hay cuatro importantes métodos auxiliares: a) el hallazgo y la determinación de las premisas; b) la diferenciación de la equivocidad de las expresiones lingüísticas, y la diferenciación entre las varias determinaciones categoriales; $c$ ) el hallazgo de las diferencias genéricas y de las específicas; d) el hallazgo de las similitudes entre los diversos géneros. Dice Aristóteles que hablamos de topos (topoi), tópicos, en relación con las conclusiones dialécticas y retóricas. Los topos o tópicos se refieren a objetos jurídicos, morales, políticos, también físicos, y de muchas otras clases. En los tópicos se da el más y el menos. De los tópicos puede derivarse un silogismo o un entimema, si bien esto suceda de modo particular, en cada una de las disciplinas. Según Aristóteles, son tópicos también los puntos de vista empleables plurilateralmente, aceptados en todas partes, que pueden ser usados en pro y en contra de las opiniones, y que pueden conducir a lo acertado o a lo prudente.

7 Aristóteles, Tópica, I, 1, 2, 4, 6, 7 y 8.

8 Aristóteles, Tópica, I, 1, 2-5. 
Aristóteles estudia también la técnica del debate, del diálogo, de la controversia práctica. Comienza con el arte de la pregunta: cuando se quiere preguntar, se tiene ante todo que descubrir el tópico del cual debe seguirse la conclusión dialéctica. En segundo lugar, se tiene que establecer la pregunta particular; y ponerla en un orden determinado; y, finalmente, presentarla al otro en forma adecuada.

Ahora bien, en todo caso resulta claro que, para Aristóteles, la dialéctica nunca es filosofía o ciencia en sentido estricto, pues la dialéctica no investiga la verdad tal y como ésta es buscada y establecida en las ciencias teóricas.

Aristóteles concibe la dialéctica como una especie de argumento (basado sobre opinión y probabilidad), en contrate con el argumento científico que se basa sobre principios que enuncian las causas y definen las naturalezas de modo unívoco.

Aristóteles ${ }^{9}$ habla de que hay dos clases de razón: "una con la cual contemplamos de entre las cosas aquellas cuyos principios no admiten ser de otra manera; otra, con la cual contemplamos las que lo admiten... Llamemos, pues, a la una, científica; y a la otra, calculadora, porque deliberar y calcular son aquí lo mismo, pues nadie delibera sobre cosas que no admiten ser de otra manera". Aparece, pues, con toda claridad, que Aristóteles distingue entre lo que llamariamos razón pura de tipo matemático, o físicomatemático, la razón de la cual él se ocupó en su Organon, y otro tipo de razón que, a diferencia de la primera, no tiene el carácter de exactitud, de precisión, de exclusividad, la cual es la que se aplica a problemas respecto de los cuales cabe una apreciación, en la que puede darse un más y un menos, un mejor o menos bueno, un peor o menos malo, y que opera no por deducciones rigorosas, antes bien por deliberación, por buen juicio, por ponderación, por apreciación. Esta segunda clase de razón es la que se podría, y aun se debería, denominar el logos de lo humano, o mejor, de la acción humana, y por lo tanto de los juicios que deben presidir a ésta. Esta es la razón que inspira la virtud de la prudencia, la cual, como es bien sabido, Aristóteles incluye dentro de las virtudes intelectuales, pero cuyo sentido direccional, cuya intención, se refiere a los asuntos de la conducta práctica.

En el pensamiento de Aristóteles sobre estos temas hay un punto, desde luego bien conocido, pero sobre el cual quizá no se ha hecho suficiente hincapié, y cuya reelaboración tal vez pueda producir un mayor éxito en el análisis de la lógica de la acción humana: se trata del punto de la relación entre la dialéctica y la virtud de la prudencia.

Aristóteles se ocupa de la prudencia no sólo en su Ética Nicomaquea sino también en su Tópica. Esto pone claramente de manifiesto que la prudencia constituye una de las especificaciones más importantes del pensamiento tópico y dialéctico o sea en torno a los problemas concretos, en relación con

9 Aristóteles, Tópica, I, 1 y 2. 
la conducta humana. En su Tópica, se plantea Aristóteles algunas cuestiones sobre la relación entre las especieś y los géneros y de los géneros entre sí; $y$, a este respecto, menciona que muchos sostienen que la prudencia es tanto virtud como conocimiento, y que ninguno de esos dos géneros se halla comprendido dentro del otro; aunque ciertamente no todos admiten que la prudencia sea conocimiento. No obstante, si alguien admite la verdad de este aserto, entonces tendrá que estar necesariamente de acuerdo con que los géneros del mismo objeto deben hallarse subordinados el uno al otro, o ambos bajo un mismo género, que es lo que efectivamente sucede en este caso con la virtud y el conocimiento, pues ambos caen bajo el mismo género; pues cada uno de los dos es un estado y una disposición.

En su Ética Nicomaquea ${ }^{10}$ Aristóteles, al tratar de las virtudes intelectuales, expone la diferenciación entre ciencia y prudencia. La ciencia se ocupa de lo que es como es de modo necesario: de las cosas que son, por necesidad absoluta, eternas, de las cosas eternas que son inengendrables e incorruptibles. "A más de esto, toda ciencia es capaz... de ser enseñada, y todo lo que es objeto de ciencia puede ser aprendido. Toda enseñanza, por su lado, parte de conocimientos previos..., enseñando unas veces por inducción, otras por silogismo. La inducción es el punto de partida aún para el conocimiento de lo universal, mientras que el silogismo procede de proposiciones universales. Hay principios de los cuales procede el silogismo, pero que no pueden probarse por silogismo, sino que tienen que serlo por inducción. - En conclusión, la ciencia es un hábito demostrativo. . . Siempre que alguno tiene una convicción de cualquier modo y le son conocidos los principios sabe con ciencia."

En otro pasaje, añade Aristóteles que "con relación a la prudencia podemos comprenderla considerando cuáles son las personas que llamamos prudentes. - Lo propio del prudente parece ser el poder de deliberar acertadamente sobre las cosas buenas y provechosas para él, no parcialmente, como cuáles son buenos para la salud o el vigor corporal, sino cuáles lo son para el bien vivir en general... Llamamos prudentes con relación a alguna cosa a los que calculan bien lo conveniente a cierto fin que no es objeto del arte".

$Y$ a continuación, produce Aristóteles una distinción de enorme alcance, la distinción que media entre el conocimiento evidente o demostrado, por una parte, y la deliberación, por otra parte. "Nadie delibera sobre cosas que no pueden ser de otra manera." Toda vez que la ciencia va acompañada de demostración, y que no hay demostración de cosas cuyos principios pueden ser de otra manera (puesto que todo en ellas puede ser de otra manera), y que, en fin, no es posible deliberar sobre las cosas que son necesariamente, la prudencia no podrá ser ni ciencia ni arte. No podrá ser ciencia, porque lo que es materia del obrar puede ser de otra manera; no podrá ser arte, 10 Aristóteles, Ética Nicomaquea, VI, 3 y 5 . 
estricto o más retringido, que se refiere a los problemas y a las resoluciones de un individuo sobre aquello que atañe, desde el punto de vista ético, a sus propias decisiones, en vista del bien vivir. Más adelante menciona cualidades pertenecientes al ejercicio de la prudencia; la consideración, la indulgencia, el espíritu equitativo, la comprensión, la intuición, la experiencia.

Se ha dicho que Cicerón concibió su tarea como la de hacer descender la filosofía desde el firmamento y darle cabida en las habitaciones y en las ciudades de los hombres. Así, Cicerón propuso hacer retornar la "sabiduría" a nexos más estrechos con la "elocuencia" $\mathrm{y}$, de ese modo, aumentar su influencia sobre la vida humana. Cicerón dividió el discurso o la argumentación, ars disserendi, en dos partes: el arte del descubrimiento o invención que es llamada tópica; y el arte del juicio, de la prueba, que es llamada por él dialéctica. Cicerón reconoce que Aristóteles contribuyó a ambas ramas. Y Cicerón dedicó a la tópica una obrita que, por cierto, fue muy apreciada en la Edad Media, obrita de menos rango que el estudio de Aristóteles, y que fue dedicada precisamente a un jurista, a C. Trebatius Testa. Así como es fácil encontrar o descubrir los objetos que están ocultos cuando se conoce el lugar donde se hallan, asi cuando queremos investigar cualquier materia, hay que conocer los tópicos, es decir, los lugares desde los cuales podemos extraer el asunto que nos ocupa. Cicerón procedió a una ordenación teórica de los tópicos; y, además, estableció un catálogo de tópicos, para facilitar la utilización de éstos.

Además, Cicerón en su obra De re publica empleó lo que describía como un "nuevo método" en la filosofía política, consistente en combinar las virtudes de los griegos y evitar los errores en que éstos incurrieron.

Ese nuevo método no se basaba ni en la especulación acerca de un Estado ideal no existente, ni en las diversidades concretas de los Estados reales y efectivos, antes bien, se fundaba sobre la historia de la República Romana, que ofrece criterios empíricos de verificación y eficacia para las instituciones prácticas políticas, desenvueltas no por el genio de un hombre ni de una generación sino por obra de muchos hombres y muchas generaciones. Cicerón propugnaba la elección de lo que parezca mejor, de acuerdo con el conocimiento, la sabiduría y la experiencia que se posea; y, de modo similar al de Sexto Empírico, tendía a descartar todo dogmatismo.13

Cabe advertir en esta parte del pensamiento de Cicerón la presencia de algunos de los rasgos más destacados y más característicos de la jurisprudencia romana. Se ha dicho que una de las notas más importantes en el desenvolvimiento del Derecho romano es la de la primacía de la acción sobre el pensamiento puro, así como también una muy fina percepción de las sin-

13 Sobre la dialéctica de Cicerón, véase $\mathrm{R}$. McKeon, Introduction to the Philosophy' of Cicero; Marcus Tullius Cicero, Brutus, On the Nature of the Gods, On Divination, On Duties, University of Chicago Press, 1950. 
gularidades concretas de cada situación. La característica de que en Roma el Derecho más que objeto de especulación pura, fuese sobre todo factor en la vida práctica, no es sólo la expresión dè un peculiar temperamento de los romanos, sino que es algo más, y de mayor importancia: es la expresión de una especial capacidad y de un magistral dominio del pensamiento sobre los problemas, del pensamiento de tipo dialéctico o argumentativo. Así, en el auténtico Derecho romano y en la genuina jurisprudencia elaborada por sus grandes jurisconsultos, no hallamos apenas construcciones jurídicas a priori, ni propósitos de sistematización. Eso no representa una casualidad, ni muchísimo menos una deficiencia. Por el contrario, constituye la clara intuición de cuál es la índole del razonamiento jurídico, índole por completo diferente de la razón sistemática, del proceso deductivo, de la construcción cerrada. La verdadera índole del Derecho y de la jurisprudencia de Roma fue por completo oscurecida, deformada, por la funesta labor de los pandectistas alemanes del siglo XIX, imbuidos de un prurito sistemático rayano casi en la monomanía. Esta justa observación no implica un desconocimiento de otros muchos grandes méritos de aquellos pandectistas, en cuyas obras hallamos sin duda realizaciones y logros muy estimables. Pero sucede que los pandectistas alemanes constituyeron el analogon, el pendant, de la Escuela de la Exégesis en Francia, en suma, de la indebida proyección del espíritu cartesiano al campo de los contenidos jurídicos. Por eso cabe exclamar con justificada razón: ¡bienaventurados sean los jurisconsultos romanos, pero Dios se apiade misericordiosamente de tantos y tantos romanistas del siglo $\mathrm{xr}$, quienes desfiguraron la índole auténtica de la obra de los primeros!

$Y$ es curioso advertir que precisamente en nuestros días va extendiéndose cada vez más y más la opinión de que las dos cumbres más altas en la historia del Derecho se hallan representadas por los jurisconsultos romanos clásicos, y por los jueces del common law, especialmente en nuestros días. Son muchas las opiniones en este sentido; y como ejemplo, por cierto muy egregio, recordemos a Radbruch quien en los últimos años de su vida dio testimonio de su creciente y fervoroso entusiasmo por el mundo del common law. Y sucede que esta opinión se basa precisamente en el hecho de que en esas dos realidades jurisprudenciales no se cayó en el nefasto prurito de un sistematismo, imposible en materia de los contenidos de la jurisprudencia, antes bien, por el contrario, se ha practicado la vía del pensamiento aporético, problemático o argumentativo.

En efecto, el método de los más grandes jurisconsultos romanos fue el de la dialéctica, en el sentido clásico y originario de esta palabra: la ponderación de las realidades, -tratando de entender el sentido de ellas-, el darse cuenta de que cada día surgen nuevas realidades antes no previstas, la incorporación creciente a la órbita de la valoración jurídica de nuevos intereses dignos de protección. Por eso se ha observado por muchos, entre ellos, por 
Miguel Reale, ${ }^{14}$ que no se puede encontrar en Roma ni durante la República ni durante el Imperio, ninguna construcción jurídica sistemática, antes bien, el cuadro de una serie de instituciones particulares que fueron siendo elaboradas paulatinamente a medida y bajo el conjuro de exigencias inmediatas.

Viehweg ${ }^{15}$ a través de finísimos y definitivos análisis ha puesto en evidencia que el desarrollo del Derecho romano, así como de la labor tanto teórica como práctica de los jurisconsultos, no se desenvolvió por la línea sistemática, antes bien, a través de los caminos de la tópica, esto es, del pensamiento suscitado por los problemas prácticos en materia jurídica: tanto aquellos que requerían el establecimiento de reglas generales, o por lo menos relativamente generales (esto es, admitiendo excepciones a las mismas), como también las cuestiones singulares que demandaban una solución concreta e individualizada. En la jurisprudencia romana las cosas se desenvuelven como si el caso planteado - cualquiera que este caso sea- constituyese el conocimiento de toda la ciencia, la cual tuviera que ser inventada y desenvuelta a partir de ese punto; es decir, en forma de una especie de continua investigación dialéctica de carácter abierto. Los juristas romanos no tomaron el Derecho como algo simplemente dado, antes bien, como algo que debe ser proseguido y reelaborado responsablemente, participando en esta labor la personalidad entera del jurista, no sólo mediante funciones intelectuales, sino también y principalmente, mediante funciones éticas. Los grandes juristas romanos llevaban a cabo su labor mediante un procedimiento de tanteo en el sentido de la tópica o, mejor dicho, de la dialéctica. Esta tradición renació y fue seguida en la obra de los glosadores (por ejemplo Accursio, Bártolo, etc.), en las de los postglosadores y en la de los comenristas; y dominó inatacada hasta el siglo xvi, después del cual todavía siguió, aunque ya bajo algunos ataques y algunas impugnaciones, hasta entrado el siglo xvir.

\section{Algunas consideraciones sobre la dialética y tópica}

Según Viehweg, lo más importante en la tópica consiste en que ella constituye la técnica del pensamiento que se orienta hacia el problema. Se trata, en suma, de lo que se ha llamado aporias o pensamiento aporético, es decir, el pensamiento que viene suscitado por el problema que asedia y que resulta inesquivable, y que suscita aquella situación que Boecio llamó dubitatio. Se reconoce el problema $-\mathrm{y}$ se trata de un problema de conducta práctica-

14 Véase Miguel Reale, "O Conceito de 'ratio naturalis' entre os jurisconsultos romanos e Santo Tomás de Aquino", en Rev. da Faculdade de Direito da Univ. de São Paulo, vol. XXIV, 1943 .

15 Véase, Theodor Viehweg, Topik und Jurisprudenz, Verlag C. H. Beck, Munich, 1959, pp. $15-26$. 
como algo dado, y como algo que nos dirige, es decir, como lo que suscita o pone en marcha al pensamiento.

El pensamiento sobre los problemas, el pensamiento problemático, se diferencia netamente del pensamiento sistemático. Podríamos describir el pensamiento sistemático $\longrightarrow$ al menos el ideal o desideratum de éste- de la siguiente manera: se arranca de una premisa evidente, autosuficiente, irrefragablemente innecesaria, de la cual por vía de derivación deductiva son inferidas toda una serie de proposiciones concatenadas orgánicamente entre sí. Desde el punto de vista del sistema, si uno cree tropezar con un problema que no quepa dentro de aquél, debe rechazar tal problema, por considerarlo como mal planteado. Si se supusiese el caso extremo de que no hubiera nada más que un solo sistema, entonces todos los problemas serían clasificados y articulados dentro de tal sistema; y los problemas bien planteados quedarían resueltos dentro del sistema; mientras que los que no fuesen solubles dentro de éste deberían ser desechados como meras apariencias de problemas, como planteamientos incorrectos. Por el contrario, el pensar aporético, el pensamiento que parte de los problemas y se concentra sobre éstos, procede a la inversa. El pensamiento aporético no implica que se niegue que pueda haber un sistema - dentro del cual pudiera ser ubicado el problema en cuestión- ni siquiera duda inevitablemente de que tal sistema pueda existir, pero no conoce ese sistema ni dispone de medios para establecerlo o construirlo; y, entonces, lo que hace es irle dando vueltas al problema una y otra vez, ir iluminando las varias facetas o vertientes del mismo, ir ponderando, sopesando, apreciando, los diversos componentes y las varias dimensiones que en él intervienen, para llegar al fin al hallazgo de una conclusión, la más probable, la que parezca ofrecer mejores visos de prudencia, de adecuación, de mayor acierto en cuanto a los resultados prácticos. ${ }^{16}$

El pensamiento dialéctico, o tópico, no se presenta, no puede presentarse jamás como un todo cerrado, antes bien, como un proceso abierto y elástico, que se vale sobre todo del método de la interpretación o, mejor dicho, de la re-interpretación, la cual se preocupa de hallar nuevas posibilidades de comprensión sin lesionar las anteriores, cuando surgen nuevos problemas, cuando aparecen nuevos puntos de vista.

Mientras que en el pensamiento sistemático una premisa debè ser clasificada o como "verdadera" o como "falsa", en cambio, dentro del pensamiento problemático, dialéctico o tópico, las premisas son calificadas muchas veces como "relevantes", “irrelevantes", "admisibles", "inadmisibles", "aceptables", "inaceptables", "defendibles", "indefendibles", etc.; e incluso son clasificadas en grados intermedios, así como "apenas defendibles", "todavía defendibles".

16 Véase Nicolai Hartmann, "Diesseits von Idealismus und Realismus", en Kant-Studien, tomo XXIX, 1924 . 
3. Pensamiento problemático, dialéctica y tópica en la Antigüedad Cristiana $y$ en la Edad Media

El pensamiento problemático, y los métodos dialécticos o tópicos, penetraron en la cultura cristiana sobre todo a través de Cicerón, aunque haciendo a un lado la tendencia de éste hacia una actitud relativamente escéptica, en el sentido de la Academia. San Ambrosio aplicó algunos de esos métodos - pero habiéndoles rebanado toda inclinación que pudiese llevar a actitudes escépticas-, a la interpretación de las Sagradas Escrituras. San Agustín, en alguna medida, fue convertido a la filosofía bajo la influencia de Cicerón, y su conversión. al Cristianismo se operó en cierto modo a través de la exégesis analógica de la Biblia realizada por San Ambrosio.

Todavía a lo largo de la Edad Media persiste el empleo del método dialéctico, en la acepción clásica, especialmente aristotélica. Hallamos ese empleo en varios campos: en el de la interpretación de la Biblia; en el de la jurisprudencia canónica; y como una de las artes liberales que figuraban en el trivium.17

Tanto en el campo de la teología como también en el terreno del Derecho canónico, muchas veces se operaba formulando una serie de propuestas de soluciones diferentes al problema planteado; se iba examinando cada una de ellas; se desechaban las tenidas por inadecuadas; y, por vía de oposición, se apoyaba la solución estimada como correcta.

En las obras medievales hallamos el uso de la dialéctica, o, mejor dicho, el empleo de esta palabra en varias acepciones, a menudo con alguna equivocidad. A veces, la dialéctica parece pertenecer al campo de la lógica de lo racional, propiamente deductiva; otras veces, en un sentido más amplio, se entiende por dialéctica el pensamiento mediante el cual se adquiere el conocimiento de las cosas; pero también en muchas ocasiones, tal vez en el mayor número de ellas, la dialéctica aparece como una parte especial de la lógica, diferenciada de la demostración científica y en contraste con ésta, como una especie de argumentación que se refiere a las probabilidades y a las opiniones.

Sin embargo varios filósofos medievales usan a veces las palabras "lógica" y "dialéctica" como términos sinónimos. Así, por ejemplo: Boecio, Casiodoro, San Isidoro de Sevilla, etcétera. ${ }^{18}$

Pero la distinción aristotélica entre la prueba demostrativa por una parte, y el razonamiento dialéctico por otra, aparece de nuevo en las obras de San Buenaventura y en las de Santo Tomás, quienes tratan la dialéctica, como razonamiento de lo probable y como "tópica", la cual llega a aparecer

17 Véase R. Mckeon, op. cit. en la nota 3, p. 9.

18 Véase op. y loc. cit. en la nota precedente (17), pp. 9-19. 
muy próxima a la retórica. En este sentido, la dialéctica es un arte de la discusión o de la refutación, que trata de evitar un dogmatismo preconcebido, y que se encamina al descubrimiento y al cálculo de las probabilidades $y$ al juicio sobre las opiniones.

Santo Tomás de Aquino (S.T.I-II Q. ${ }_{5}^{6}$ ) dice que la prudencia es la recta razón respecto de las cosas que uno debe hacer; y distingue entre la recta razón especulativa que se refiere al objeto de la ciencia, por una parte, y el intelecto práctico que tiene como objeto la prudencia. En muchos de sus textos Santo Tomás habla de la prudencia como "buen consejo".

En otro lugar de la Suma Teológica (II, II Q. 181) Santo Tomás afirma que la prudencia es una virtud que pertenece a la vida activa. Aunque la prudencia pertenezca a las virtudes intelectuales, su objeto se refiere sobre todo a las virtudes morales. Es "virtus intellectuallis circa moralia". A este respecto, Gómez Robledo observa que "la prudencia está, como tiene que ser, en la más estrecha interdependencia con la virtud moral, y ambas se implican mutuamente en una relación que Aristóteles ha escrutado con admirable sagacidad y como genial conocedor que fue de la naturaleza humana".

4. Eclipse de la dialéctica por obra del espiritu cartesiano, y reivindicación de ella por Vico

En términos generales, aunque no absolutos, el método cartesiano y todas las derivaciones y consecuencias de él determinaron un predominio, si es que no la pretensión de exclusividad, del raciocinio de tipo matemático, que debe conducir a la construcción de un sistema total, coherente, articulado, unitario, todas cuyas proposiciones alcancen el grado de evidencia indiscutible y univoca. La meta cartesiana es la consecución de "ideas claras y distintas"; y, así, Descartes dijo: siempre que dos hombres tienen un juicio contrario sobre la misma cosa, podemos estar ciertos de que uno de los dos se equivoca. Es más, ninguno de los dos posee la verdad, porque si tuviera una idea clara y distinta de ella, podría exponerla a su adversario de tal modo que acabase por forzar la convicción de éste. Así, Perelman ${ }^{19}$ observa

19 Véase Chaim Perelman, De la justice, Bruselas, 1945; "Raison eternelle et raison historique", en L'homme et l'histoire, Actes du VI Congrès des Societés de Philosophie de Langue Française, Presses Universitaires de France, París, 1952; "Rhétorique et Philosophie", en De la preuve en philosophie, Presses Universitaires de France, París, 1952; "La Justice", en Revue Internationale de Philosophie, Bruselas, 1957, Fasc. 3; "Self-Evidence and Proof", en Philosophy, oct. 1958; Logique formelle, logique juridique, Univ. de Bruselas, 1959; "Pragmatic Arguments", en Philosophy, enero de 1959; "La distinction du fait et du droit: Le point de vue du logicien", en International Review of Philosophy of Knowledge, Griffon, Neuchatel, 1960; "Jugements de valeur, justification et argumentation", en Revue Internationale de Philosophie, Bruselas, 1961, Fasc. 4; "Ce qu'une réflexion sur le droit peut apporter au philosophie", en Archives de Philosophie du Droit, № 7. Sirey, París, 1962; "El Ideal de Racionalidad y la Regla de Justicia", en Diánoia: 
atinadamente que el lógico de tipo cartesiano se siente a sus anchas tan sólo dentro del campo del estudio de las pruebas analíticas, que son las que presentan un carácter de necesidad. La tradición del pensamiento cartesiano, el cual busca sobre todo y por encima de todo la "evidencia", desdeña cualquiera proposición que no posea ese carácter de lo obvio, de lo indiscutible, de lo exacto, de lo preciso.

Bajo el impetu predominante, diríamos casi arrollador, de ese tipo car. tesiano de pensamiento "matematizante", el razonar dialéctico -en el sentido clásico- quedó si es que no por entero eclipsado, al menos muy en penumbra en el siglo xvir.

Fue Vico quien, sin desdeñar la importancia y el alcance enorme es del espíritu cartesiano, recordó, sin embargo, la justificación del método dialéctico o retórico. En efecto, Vico clasificó los métodos científicos en dos tipos: el retórico y el crítico. El método retórico constituye un legado de la Antigüedad, sobre todo de Aristóteles y de Cicerón; mientras que, en cambio, el método critico es el que pudiera llamarse cartesiano.

El nuevo método crítico, el cartesiano, consiste en hallar como punto de partida una verdad primaria, la cual no pueda ser aniquilada, ni siquiera afectada por la duda, y cuyo ulterior desarrollo, por vía de derivación deductiva, se produzca mediante procedimientos similares a los de la matemá. tica y la geometría. Ese método crítico -observó Vico- tiene sin duda ventajas, las cuales consisten en la precisión y en la exactitud; pero está lastrado también por desventajas: una pérdida o, por lo menos, una disminución de la visión prudente; una cierta atrofia de la fantasía; un empobrecimiento del lenguaje; $y$, en fin de cuentas, una falta de madurez del juicio sobre los asuntos humanos.

En cambio, Vico señala que el antiguo método dialéctico o retórico, especialmente mediante el instrumento de la tópica, toma como punto de partida el sentido común, el buen sentido, que va cambiando el camino a través del campo de las verosimilitudes; que cambia los puntos de vista según todas las circunstancias concomitantes; y que trabaja con una gran variedad de premisas. Es el método de la prudencia humana, que enseña a ponderar los componentes de cada situación, desde diversos puntos de vista, y que ayuda al hallazgo de la solución más adecuada para los problemas, y especialmente para los problemas prácticos.

Adviértase que en esas observaciones de Vico, como en general en todo el manejo de la dialéctica en el sentido clásico, aparece como idea central la

Anuario de Filosofía, Centro de Estudios Filosóficos, Universidad Nacional Autónoma de México, 1962; Le Fait et le Droit: Etude de Logique Juridique, Recueil de plusieurs travaux du Centre National de Recherches de Logique, Emile Bruylant, Bruselas, 1961, "Scepticisme morale et philosophie morale", en Morale et Enseignement, Bruselas, 1962, Fasc. 4; Justice et Raison, Presses Universitaires de Bruxelles, 1963. 
virtud de la prudencia, la cual, aunque virtud intelectual, según Aristóteles, es la que gobierna la vida moral del hombre. ${ }^{20}$

5. Demoledoras criticas en el siglo XIX y en el $\mathrm{xx}$ contra el empleo de la lógica tradicional deductiva en la Jurisprudencia, y en la vida humana en general

Desde 1884 , empezó una serie de ofensivas, cada vez más enérgicas y contundentes, contra el empleo de la lógica tradicional, es decir, de la lógica de tipo matemático, o llamada también físico-matemática, en el campo de la jurisprudencia. A las críticas sarcásticas de Jhering, ,11 siguieron a los pocos años las muy sesudas observaciones del famoso juez norteamericano Oliver Wendell Holmes 22 y el ataque de François Gény.23 A comienzos del siglo $\mathrm{xx}$ los alemanes Ehrlich ${ }^{24}$ y Kantorowicz ${ }^{25}$ aportaron nuevas impugnaciones contra el uso de la lógica tradicional para el tratamiento de los contenidos jurídicos. En 1908 un famoso abogado de París, Jean Cruet, ${ }^{26}$ puso de manifiesto cómo, en contra de la mentira convencional que era siempre enseñada, la Corte de Casación Francesa no había operado mediante métodos lógicos tradicionales, antes bien había producido, de una manera constantemente renovada, interpretaciones adecuadas y creadoras, de acuerdo con los nuevos problemas que iban surgiendo, o con las nuevas realidades que se iban presentando. Unos años después, otro jurista francés, Gaston Morin 27 hizo resaltar lo que él llamaba la revuelta de los hechos contra las interpretaciones tradicionalistas y convencionales del Código Civil.

Hay que mencionar, muy acentuadamente, los desenvolvimientos fértiles y de muy largo alcance de la jurisprudencia sociológica en los Estados Unidos, sobre todo las aportaciones de extraordinario volumen y de gran fe-

20 Véase la "Introducción" de Antonio Gómez Robledo a su traducción de la Ética Nicomaquea de Aristóteles (Versión española y notas por Antonio Gómez Robledo), Universidad Nacional Autónoma de México, 1954, págs. Lxxxvi $s$.

21 Véase Rudolf von Jhering, Scherz und Ernst in der Jurisprudenz, 1884. (Hay trad. esp. de Román Riaza, Jurisprudencia en broma y en serio, Ed. de la Revista de Derecho Privado, Madrid, 1933.)

22 Véase Oliver Wendell Holmes, The Common Law, 1882, Collected Legal Papers, 1920.

23 Véase François Gény, Méthode d'interpretation et sources en droit privé positif, París, 1899, 2a. ed., 1919 (hay trad. española, Método de interpretación y fuentes en Derecho Privado Positivo, Ed. Reus, Madrid, 2a. ed., 1925).

24 Véase Eugen Ehrlich, Freie Rechtsfindung und freie Rechtswissenschaft, Grundlegung der Soziologie des Rechtes, 1913; Die juristische Logik, 1918.

25 Véase Gnaeus Flavius (Hermann Kantorowicz), Der Kampf um die Rechtswissenschaft, $195^{6 .}$

26 Véase Jean Cruet, La vie du droit et l'impuissance des lois, Paris, 1908.

27 Véase Gaston Morin, La révolte du droit contre le Code, 1915; La révolte des faits contre le Code, 1920. 
cundidad de Roscoe Pound ${ }^{28}$ y también de Benjamin Cardozo, ${ }^{29}$ Louis Brandeis ${ }^{30}$ y Julius Stone. ${ }^{31}$

Desde la segunda década de este siglo, en Alemania cobra extraordinaria influencia la escuela llamada de la jurisprudencia de intereses, cuyos principales representantes son Rümelin,, ${ }^{32}$ Oertmann ${ }^{33}$ y Heck, ${ }^{34}$ la cual orienta la labor del jurisconsulto, y sobre todo del juez, hacia la obediencia, no a las palabras de la ley, sino a los juicios de valor en los cuales real y positivamente se inspira la ley.

En la historia de los ataques y de las críticas contra el manejo de la lógica tradicional, de la lógica de lo racional, en el campo jurídico, ha desempeñado y sigue desempeñando una gran influencia el conjunto de aportaciones del movimiento del realismo jurídico norteamericano, cuyos más ilustres exponentes fueron Karl Llewellin ${ }^{35}$ y Jerome Frank., ${ }^{36}$ También es justo mencionar en direcciones paralelas o emparentadas a las referidas, la aportación del jurista español Joaquín Dualde, ${ }^{37}$ y del iusfilósofo argentino Carlos Cossio.38

Todos esos estudios producidos en torno a los problemas planteados por la interpretación del Derecho y por la misión jurisdiccional, representan un recobrar, dentro del campo jurídico, la conciencia de que para los asuntos de la conducta humana no vale la lógica tradicional, ni la de Aristóteles (se entiende la del Organon), Bacon, etc., ni siquiera la fenomenología de Hus-

28 Roscoe Pound, autor de un gran número de libros y de artículos a lo largo de más de medio siglo, ha recopilado y reelaborado sus aportaciones en la obra monumental Jurisprudence, West Publishing Co., St. Paul, Minnesota, 1959, que comprende cinco gruesos volúmenes.

29 Véase Benjamin Cardozo, The Nature of the Judicial Process, Yale University Press, 1921; The Growth of the Law, Yale University Press, 1924; The Paradoxes of the Legal Science, Columbia University Press, 1928.

30 Véase The Words of Justice Brandeis, Edited by Solomon Goldman, Schuman, Nueva York, 1953 .

31 Véase Julius Stone, The Province and Function of the Law, A Study in Jurisprudence, Law as Logic, Justice and Social Control, 2a. ed., Harvard University Press, 1950.

32 Véase Max Rümelin, Die Gerechtigkeit, 1920; Die Billigkeit im Recht, 1921; Rechts. gefühl und Rechtsbewusstsein, 1925; Erlebte Wandlungen in Wissenschaft und Lehre, 1930.

33 Véase Paul Oertmann, Soziologische Rechtsfindung, 1914; Interessen und Begriffe in der Rechtswissenschaft, 1931.

34 Véase Philipp Heck, Das Problem der Rechtsgewinnung, 1912; Gesetzauslegung und Interessenjurisprudenz, Rechtsemeuerung und juristischer Methodenlehre, 1936; Rechtsphilosophie und Interessenjurisprudenz, 1937.

35 Véase Karl N. Llewellyn, Jurisprudence: Realism in Theory and Practice, University of Chicago Press, 1962, obra en la cual aparece recopilado, y reelaborado, lo principal del pensamiento de su autor.

36 Véase Jerome Frank, Law and the Modern Mind, 1930, 6a. ed., 1949; Courts on Trial, 1949.

37 Véase Joaquín Dualde, Una revolución en la lógica del Derecho. (Concepto de la interpretación del Derecho Privado), Editorial Bosch, Barcelona, 1933.

38 Véase Carlos Cossio, El Derecho en el Derecho Judicial, Edit. G. Kraft, Buenos Aires, 1945 . 
serl, ni las lógicas simbólicas. Se trata de un tomar de nuevo, en el campo especial de lo jurídico, la actitud representada por la dialéctica o tópica clásica; pero circunscribiendo el problema al área de la jurisprudencia. Ahora bien, lo que ha sucedido en el terreno jurídico representa tan sólo un caso de una cuestión mucho más general: de la cuestión concerniente al logos de lo humano, del cual el área jurídica constituye tan sólo un sector, al lado de otros sectores, como son el de la política, el de la economía, en suma, el ámbito todo de los problemas prácticos del comportamiento humano.

Al nivel filosófico general este tema fue planteado de nuevo, entre otros, por Dilthey, Dewey, Ortega y Gasset y Collingwood.

Por mi parte, yo, modestamente, aunque con especial atención enfocada a la interpretación del Derecho, abordé de nuevo el tema del logos de lo humano, o lógica de lo razonable - a diferencia de la lógica de lo racional-, en un libro que publiqué en $195^{6.39}$

También con especial contemplación en torno a los temas jurídicos, pero con alcance que rebasa las fronteras de éstos, hay que prestar muy especial atención a las contribuciones de Léon Husson, ${ }^{40}$ del ya citado Theodor Viehweg ${ }^{41}$ y de Juan David García Bacca. ${ }^{42}$

De algunos de los esclarecimientos suministrados por Viehweg me he ocupado ya en páginas precedentes de este estudio.

Léon Husson, filósofo francés, ha elaborado un profundo análisis de la experiencia jurídica, análisis en el cual muestra que esa experiencia abarca siempre una relación recíproca entre hechos reales, que comprenden problemas y propósitos y juicios de valor. Ese análisis de la experiencia jurídica incluye ideas directrices y aclaraciones de gran importancia, tanto para el legislador como para la interpretación judicial. El pensamiento lógico tradicional opera con conceptos puros y parte de principios puros, deduciendo de tales conceptos y principios conclusiones por vía silogística, y de manera

39 Véase Luis Recaséns Siches, Nueva filosofia de la interpretación del Derecho, Publicaciones de Diánoia, Centro de Estudios Filosóficos de la Universidad Nacional Autónoma de México, Fondo de Cultura Económica, México, 1956. Véase también del mismo autor: "Unicidad en el método de interpretación del Derecho", en el volumen Homenaje ofrecido al Prof. Luis Legaz Lacambra, Universidad de Santiago de Compostela, 1960; "Interpretación del Derecho", artículo en la Enciclopedia Jurídica OMEBA, Buenos Aires, 1961; "Rivoluzione Teorica e Pratica nell'Interpretazione del Diritto", en Ritista Internazionale de Filosofia del Diritto, Roma, julio-agosto, 1962; "The Logic of the Reasonable as Differentiated from the Logic of the Rational (Human Reason in the Making and the Interpretation of the Law)" en Essays in Jurisprudence in Honor of Roscoe Pound, BobbsMerril, Indianapolis-New York, 1962.

40 Véase Léon Husson, Les transformations de la responsabilité: Étude sur la Pensée Juridique, Presses Universitaires de France, París, 1947.

41 Véase op. cit., en la nota 15.

42 Véase Juan David García Bacca, Planes de lógica juridica, Editorial Sucre, Caracas, $195^{8 .}$ 
ilimitada. Por el contrario, Husson afirma y muestra que el Derecho no es un sistema que permita inferir conclusiones mediante procedimientos deductivos. El Derecho se halla infinitamente lejos del pensamiento de tipo matemático. Ni la ciencia jurídica ni el método jurídico se proponen adquirir un conocimiento puro ni de ideas ni de hechos. En cambio, el método jurídico enfoca hechos desde puntos de vista teleológicos y axiológicos. Consiguientemente, el juez no puede nunca considerar las leyes en vigor como un todo autosuficiente. Por el contrario, el juez debe enfocar las leyes tan sólo como expresiones imperfectas de un pensamiento subyacente, pensamiento que nunca queda ni puede quedar expresado de modo pleno en las fórmulas legales. Se trata de un pensamiento dinámico y abierto, del cual deben extraerse, constantemente, nuevas y nuevas inspiraciones, de modo sucesivo, para afrontar nuevos hechos y nuevas necesidades. El Derecho no es un tema que pertenezca a la lógica. Por el contrario el Derecho es un asunto de buen juicio, de prudente apreciación, de estimaciones valorativas.

Juan David García Bacca, gran metafísico, pero también eminente especialista en todos los campos de la lógica (desde Aristóteles hasta los más recientes desarrollos de las lógicas simbólicas) ha demostrado, definitivamente, decisivamente, que la lógica pura, en cualquiera de sus varios niveles y de sus distintas manifestaciones, no puede ser aplicada al campo de lo jurídico. El análisis de las normas jurídicas de cualquier clase -legales, consuetudinarias y judiciales - pone de manifiesto que en el campo del Derecho nunca hallamos auténtica lógica; y que, por el contrario, lo que encontramos son elementos y estructuras "logoides". García Bacca usa este término logoide en analogía a la diferencia que existe por ejemplo entre anthropos y anthropoide o entre álcali y alcaloide o entre astro y asteroide. Para caracterizar los "logoides" García Bacca ha aceptado también mi terminología de "lo razonable". Después de una serie de análisis finísimos, agudos, e irrebatibles, García Bacca llega a la conclusión de que no hay ningún principio que exija que el Derecho se ajuste a los requerimientos de la lógica pura. En el Derecho hay una dimensión intensiva -mandar, ordenar-, por entero desconocida en el ámbito de la lógica pura. Hay también, y debe haber, una flexibilidad, una adaptabilidad, un admitir excepciones justificadas, todo lo cual no cabe dentro del marco de la lógica tradicional descrita. En el Derecho no hay definiciones auténticamente tales; lo que hay es otra cosa: determinaciones creadoras que emanan del autor de las normas jurídicas.

Como mencioné ya antes, uno de los primeros en plantear de nuevo al nivel de la filosofía en términos generales el problema de un campo de la lógica diferente al campo de lo "racional, sistemático, deductivo", fue Dilthey, con su teoría de la "razón histórica". ${ }^{43}$ Este punto fue profun43 Véase Wilhelm Dilthey, Der Aufbau der geschichtlichen Welt in den Geisteswissen- 
dizado y esclarecido muchísimo más gracias a la obra de José Ortega y Gasset, ${ }^{44}$ pues él mostró que la razón física, naturalista, fracasó totalmente en el estudio del hombre. Cuando las llamadas ciencias del espíritu quisieron llenar la misión en la que fracasaran las ciencias naturales, el conocimiento del hombre, fallaron también en ese empeño. Los fenómenos humanos mostraron también la misma resistencia, la misma indocilidad a dejarse apresar por los conceptos de las ciencias del espíritu. Aquel concepto de espíritu representaba un naturalismo larvado y, por ello, inoperante frente a las concepciones naturalistas, sus presuntas enemigas. El espiritu es identidad $y$, por tanto res, cosa, todo lo sutil, etérea que se quiera; el espíritu tiene una consistencia estática: es ya y desde luego todo lo que es y va a sèr. Era tan evidente la rebeldía de lo humano a ser concebido estáticamente, que pronto hubo de intentarse - Leibniz - superar el estatismo haciendo consistir el espíritu en actividad. IIntento vano!, porque esa actividad, como toda actividad, es siempre una y la misma, fija, prescrita, ontológicamente inmóvil. En Hegel el movimiento de espíritu es pura ficción, porque es un movimiento interno al espíritu, cuya consistencia es, en su verdad fija, estática y preestablecida. Toda identidad, cuyo ser consiste en ser idéntico, posee evidentemente ya, y desde luego, todo lo que necesita para ser. Por esta razón, el ser idéntico es el ser substante o substancia, el ser que se basta a sí mismo, el ser autosuficiente. Esto es la cosa. Ahora bien, "el hombre no es cosa ninguna sino un drama - su vida, un puro y universal acontecimiento que acontece a cada cual y en que cada cual no es a su vez sino acontecimiento. Todas las cosas, sean las que fueren, son meras interpretaciones que se esfuerza en dar a lo que encuentra. Lo que encuentra son puras dificultades y puras facilidades para su vida. El hombre es una entidad infinitamente plástica de la que se puede hacer lo que se quiera. La vida humana no es una entidad que cambia accidentalmente, sino, al contrario, en ella la "sustancia" es precisamente cambio, lo cual quiere decir que no puede pensarse eleáticamente como sustancia. Como la vida es un "drama" que acontece, y el "sujeto" a quien le acontece no es una "cosa" aparte y antes de su drama, sino que es función de él, quiere decirse que la "sustancia" sería su argumento. No hay que decir, pues, que "el hombre es sino que vive". Ortega y Gasset mostró que la razón matemática, la razón pura, no es más que una especie de la razón. Entenderla como la razón, sin más, es tomar la parte por el todo: una falsedad. Junto a la razón matemática y eterna, y por encima de ella, está la razón vital. Esta razón no es menos razón que la otra. Se trata de una razón rigorosa,

schaften, Teubner, Leipzig y Berlín, 1927. (Hay trad. esp. por Eugenio Imaz, El mundo histórico, Fondo de Cultura Económica, México, 1944.)

44 Véase José Ortega y Gasset, Obras Completas, Revista de Occidente, Madrid, 1947, tomo VI, págs. $25-44$. 
pero capaz de aprehender la realidad temporal de la vida: es lo que se llama también la razón histórica, una razón narrativa. Para compreder algo humano, personal o colectivo, es preciso contar una historia. La vida sólo se vuelve un poco transparente ante la razón histórica. En suma, el hombre no tiene naturaleza sino que tiene historia. O lo que es igual: lo que la naturaleza es a las çosas, es la historia con respecto al hombre.

Collingwood,45 coincidiendo en esto con Ortega y Gasset, y después de éste, observó que la "ciencia de la naturaleza humana" quebró, porque incurrió en el gravísimo error de querer usar un método parecido al de las ciencias naturales. El elemento realmente nuevo en el pensamiento de hoy en día es centrar el estudio de lo humano alrededor de la historia. La historia ocupa en el mundo presente una posición análoga a la que la física ocupó en el siglo xvir: se reconoce a la historia como una forma especial y autónoma de pensamiento, últimamente establecida, cuyas posibilidades aún no han sido completamente éxploradas. La historia no es la descripción de los sucesivos acontecimientos humanos, sino el estudio de aquellos acontecimientos que son la expresión externa del pensamiento.

No es este lugar el adecuado para discutir críticamente las doctrinas de Ortega y Gasset y Collingwood. Creo que en ellas hay mucho de certero; pero también opino que hay una exageración inadmisible. Pero analizar críticamente este punto no es el tema del presente trabajo. Mencioné a Ortega y Gasset y a Collingwood como autores de importantes contribuciones a la exploración del logos de lo humano.

El filósofo norteamericano John Dewey ${ }^{46}$ repudia la lógica deductiva para el tratamiento de los asuntos humanos; y sostiene que ésta debe ser sustituida por una lógica diferente, por un tipo de lógica que, en lugar de arrancar de los antecedentes, tenga su centro de gravedad en la consideración de las consecuencias; y una lógica que se aventure a la previsión de probabilidades, y deje la obsesión de deducir certidumbres; de una lógica que proceda por vía de tanteos o de contrastes con la realidad, y dispuesta, por lo tanto, a todas las rectificaciones que la experiencia o la anticipación mental de sus efectos puedan aconsejar; de una lógica orientada hacia finalidades y propósitos. Los principios generales deben ser solamente medios para estudiar, analizar y conocer los factores de la situación de que se trate. Ahora bien, al igual que otros instrumentos, deben ser modificados cuando se apliquen a nuevas situaciones, o cuando se intente obtener nuevos resultados, o cuando se apunte a la realización de nuevos propósitos.

El tema que la dialéctica clásica, de la retórica o tópica ha sido reactua-

45 Véase R. G. Collingwood, The Idea of History, Clarendon, Oxford, 1946 (Hay trad. esp. por Edmundo O'Gorman y Jorge Hernández Campos, Idea de la Historia, Fondo de Cultura Económica, México, 1952.)

46 Véase John Dewey, Studies in logical theory, 1909; The need for a recovery of philosophy, 1917; Reconstruction in philosophy, 1920; How we think, 1931. 
lizado en los últimos años por el profesor belga Chaim Perelman, ${ }^{47}$ tanto al nivel filosófico general, como también en sus aplicaciones específicas al campo del Derecho, en una serie de muy valiosos estudios sobre la argumentación, como un logos diferente del pensamiento lógico de tipo cartesiano. Según Perelman, la argumentación comprende deliberación, diálogo; comprende también el hecho de dirigirse a un público, a unos oyentes o auditores. Además incluye el hecho de establecer puntos o marcos de referencia; y abarca asimismo el propósito de hallar un juicio equilibrado, prudente, adecuado. Toda argumentación apunta a formarse un juicio práctico, a decidir sobre un problema de conducta.

\section{Ensayo de un nuevo planteamiento de la cuestión sobre la lógica de los problemas humanos}

En fin de cuentas, nos hallamos ante el problema de averiguar, mejor dicho, de analizar, en qué consista y cómo opere el logos de lo humano, en términos generales, y en sus varias especificaciones: la moral propiamente dicha en sentido estricto; las tareas cotidianas de la vida corriente, dentro del marco de lo permitido desde el punto de vista de la moral, una serie de quehaceres, de problemas prácticos sobre la propia vida, sobre un enjambre o una textura de un sinnúmero de relaciones con nuestros semejantes, en las cuales no van implicados dramáticos interrogantes ni cuestiones cruciales; las orientaciones y las decisiones en el seno de la familia, tanto en la existencia conyugal, como en las relaciones con los hijos y aun con otros parientes, y en la administración de los bienes materiales dentro del hogar; los problemas políticos; las controversias jurídicas; los asuntos económicos; etcétera.

Dejemos a un lado los temas aludidos en el primer enunciado, las cuestiones pertenecientes a la moral en sentido estricto, aquellas que se refieren al último destino del hombre, a los valores básicos que originan normas - sobre todo las prohibitivas - con validez necesaria e irrefragable; el bien moral en la más rigorosa acepción de esta palabra, lo verdaderamente bueno y lo indiscutiblemente malo; la teoría de la virtud en términos generales; la jerarquía de los valores éticos, y, consiguientemente, de los bienes morales, entre sí, y de ellos con los valores y los bienes de otras clases. Desde luego que con toda probabilidad, es más, con muchísima verosimilitud, hay sin duda el problema de la conexión entre la moral sensu stricto, y todas las otras cuestiones de conducta humana práctica, a las que acabo de aludir; y que este problema debe ser afrontado, y planteado con todo su rigor, tomando en consideración lo mismo las previas implicaciones que las consecuencias relacionadas. Pero ese problema, que es de dimensiones mayúscu-

\footnotetext{
47 Véanse obras citadas en la nota 19.
} 
las, y cuyo tratamiento requiere un afilado bisturi mental para el análisis, no es el tema del presente trabajo; y, por eso, expresamente lo hago a un lado.

El asunto de este estudio se limita a ofrecer algunas consideraciones, e incluso ellas nada más que programáticas y estimulantes, sobre el logos de la acción humana referido a las áreas de las que se ocuparon la dialéctica, retórica y tópica antiguas, así como también las renovaciones contemporáneas de ellas, las doctrinas producidas en nuestro tiempo sobre la razón vital y la razón histórica, sobre la lógica experimental referida a la acción, sobre el logos de lo razonable, etc.

Para ese tema contamos con antecedentes importantes, preñados de sugestiones, llenos de fecundas experiencias intelectuales; pero no existe en la historia toda del pensamiento filosófico una doctrina que cubra todas esas áreas, y que haya llegado a ser organizada, con profundidad y finura suficientes. Vaya por delante, y dicho sea con recalcada modestia, que yo no pretendo ni remotamente suplir esa oquedad ni llenar tal vacío. $\mathrm{Mi}$ propósito es enormemente más humilde: el de llamar vigorosamente la atención sobre la conveniencia de hacer un análisis filosófico a fondo de la estructura y de las operaciones del logos de lo humano, análisis con el cual se empiece a escribir la obra - se entiende, mejor dicho, las obras- de la cual o de las cuales todo lo anterior ha sido tan sólo prólogo certero e incitante.

El autor del presente trabajo no es kantiano ni neokantiano; pero como cualquier filósofo, por modesto que éste sea, sabe muy bien que, aun considerando el kantismo como una filosofía del pretérito, de ella hemos aprendido muchas actitudes y muchas verdades que hasta hoy sobreviven incólumes, a pesar de que la obra de Kant, algunos de sus planteamientos y muchos de sus resultados, hayan sido superados. Pues bien, hecha esta advertencia, yo querría plantear el programa para una investigación sobre el logos de lo humano en los siguientes términos: escribir la critica de la razón humana, esto es, del logos de lo razonable. $\mathrm{Y}$ tomar como punto de partida para esta investigación un factum que no hemos fabricado, que no constituye una previa elaboración intelectual de carácter científico o filosófico, sino qua lo encontramos ante nosotros como algo dado: el hecho de que frente a problemas familiares, domésticos, políticos, jurídicos, económicos, etc., los hombres deliberan, argumentan, ponderan unas razones frente a otras, buscan no la verdad, no la verdad exacta, indiscutible, sino una solución práctica aceptable, la más prudente que quepa encontrar, la que parezca adecuarse mejor a los términos de las cuestiones planteadas, la que se repute como más satisfactoria, la que se juzgue como más sensata.

Este factum, este hecho, no lo hemos fabricado los filósofos, no constituye una elaboración doctrinal, no representa el resultado de una interpretación intelectual. Por el contrario, es eso, lo que dije, un factum, un he- 
cho, ante el cual nos encontramos. $\mathrm{Y}$ ante ese hecho lo que debemos intentar hacer, es esforzarnos por entenderlo, por hallar la "peculiar razón" que lo rige, o, mejor dicho, que lo dirige. $O$, expresando lo mismo de otra manera, no vamos a llegar al intento de explicación, o de comprensión de ese hecho, partiendo de unos principios previos y superiores dentro de una construcción filosófica antecedente, de modo que el estudio de esa zona de la deliberación razonable constituyese algo así como un capítulo de esa visión filosófica total.

Claro que lo que se consiga explicar o comprender de ese logos práctico, eso será ya filosofía, será ya doctrina, será ya intento o ensayo de entender ese objeto. Pero el objeto que debe ser estudiado, ése no lo hemos producido nosotros, no lo ha engendrado ningún filósofo, antes bien, constituye un dato, con el que nos topamos. Kant no inventó él la ciencia físicomatemática de la naturaleza en la situación que ésta tenía en su tiempo, específicamente en la elaboración de Newton. Ahí estaba la física de Newton, que presentaba coherencia, pruebās, demostraciones y verificaciones, a primera vista plausibles, y que, además, mostraba su eficacia a través de sus derivaciones o hijuelas técnicas. Con respecto o frente a ese hecho cabían dos actitudes: a) la de no interesarse por él, la de despreocuparse de él, la de dejar que siguiese operando por su propia cuenta, es decir, la actitud no filosófica, la renuncia de la filosofía a tratar de ese hecho - renuncia que habría equivalido a una especie de traición de la filosofía a sí misma-; $b$ ) el intento de explicar, de comprender, ese hecho, el hecho de la ciencia físico-matemática de la naturaleza, de explicar cómo ella es posible, o lo que es lo mismo, de comprender cuáles son sus fundamentos, cuáles son sus razones, y cuáles son sus títulos de validez, así como al mismo tiempo, cuáles sean sus limitaciones, esto es, la postura auténticamente filosófica, que fue la asumida por Kant, y que engendró nada menos que su Critica de la razón pura, su gran tratado de teoría del conocimiento sobre la ciencia físico-matemática de la naturaleza.

Pero Kant se encontró además ante otro hecho: el que él llamó el factum moral. Halló el hecho de una actividad espiritual que puede llamarse "conciencia moral". El hombre oye dentro de sí lo que se trama la voz de la conciencia'moral, a través de la cual se le manifiestan unos principios, a través de la cual se formulan juicios morales, y a través de la cual se apunta a realidades trascendentes, por entero diferentes de los fenómenos de la naturaleza, y a través de la cual aparecen "razones"; pero razones diferentes de los principios del conocimiento, diferentes de los principios lógicos de la razón pura aplicada al conocimiento de la naturaleza, diferentes de la razón encaminada a determinar la esencia de los fenómenos. El factum moral incluye una serie de calificaciones: bueno, malo, moral, inmoral, meritorio, pecaminoso, etc. $\mathrm{Y}$ todos esos calificativos son aplicados 
al hombre y a su comportamiento; y en rigor (aunque a veces erróneamente se produzcan expresiones contrarias) esos predicados morales no pertenecen a las cosas, pues en rigor las cosas no son buenas ni malas, porque en las cosas no hay mérito ni demérito. Los calificativos morales no pueden predicarse de las cosas, que son indiferentes al bien y al mal; sino que sólo pueden predicarse del hombre, de la persona humana.

Algunos - por cierto de modo muy discutible - han señalado como características de la moral kantiana las siguientes: racionalismo a ultranza, formalismo puro, y rigorismo estricto. Prescindamos ahora de ocuparnos de las dos últimas notas (formalismo y rigorismo) y constriñámonos tan sólo a discutir eso del "racionalismo" de la ética kantiana. Ciertamente que la ética de Kant, su Critica de la razón práctica y sus otras obras dedicadas a los mismos problemas, constituyen una rigorosa construcción estrictamente racionalizada de filosofía ética. Pero el punto de partida de la meditación kantiana sobre la ética, no es un principio racional, ni unos principios racionales, antes bien, el hecho de que uno se encuentra ante la conciencia moral, el hecho de que en ese factum pululan y operan principios y "razones" diferentes de los principios y de las razones que operan en el conocimiento científico de la naturaleza, y en la teoría filosófica de ese conocimiento científico. Por otra parte, recordemos que más allá de la filosofía ética de Kant, pero procediendo de la misma, se abren vías para entrar en contacto directo con realidades trascendentes, nouménicas: -la libertad, la inmortalidad, Dios-, mediante lo que Kant llamó "postulados de la razón práctica". Entre el factum moral, que constituye el punto de partida, la estación de arranque, el dato para la filosofía ética, y, por otra parte, las derivaciones ulteriores de ésta que abren un nuevo camino a la metafísica - la cual había resultado inaccesible por las vías de la mera razón pura teorética-, hay ciertamente una construcción racionalizada. Pero esa construcción racionalizada tiene como cimiento no unos principios racionales, antes bien, un hecho: el hecho de la conciencia moral. Y más allá de esa construcción racionalizada, se otea un horizonte, el cual, si bien inabordable para la razón pura, en cambio, es postulado por la razón práctica.

En buena hora no seamos ya kantianos; pero, en cambio, no olvidemos muchas de las enseñanzas del kantismo, que siguen estando vivas, y pueden todavía operar como fuentes de inspiración. A Kant no se le ocurrió aplicar los principios que halló y expuso en su Crítica de la razón pura al estudio y análisis de la conciencia moral, de las razones prácticas de esa conciencia moral, de sus principios. A pesar de que Kant llame la "razón práctica" "razón pura práctica", esa denominada "razón pura práctica", aunque quiera ser pura, es diferente de la "razón pura teorética".

Sucede, pues, que hoy estamos cobrando, o, mejor dicho, recobrando, con- 
ciencia de otro factum: del factum de los asuntos humanos (políticos, juridicos, económicos) que constituyen objeto de deliberación, de discusión, de argumentación, a través de las cuales se intenta atinar en una solución, respecto de la cual no se puede predicar la nota de verdad ni su contraria de mentira, o falsedad, la de exactamente acertada o notoriamente errónea; ni la calificación de absolutamente buena o absolutamente mala; antes bien, otro tipo de calificaciones: la que parece más justa, más adecuada, más conveniente, más fructífera, más eficaz, más apropiada, menos peligrosa, más humana, más sensata, más discreta, más circunspecta, más cuerda, más juiciosa, más cauta, con mayor dosis de buen sentido, más prudente, etc. Con esa larga lista de adjetivos, entre los cuales hay dimensiones de sinonimia, pero también algunos matices diferenciales, no he intentado en manera alguna una exhibición lexicográfica. Mi propósito, al presentar ese largo elenco de adjetivos, ha sido otro: el de llamar la atención hacia el hecho. de que real y efectivamente en el lenguaje $-y$, por lo tanto, también en la conducta y en el pensamiento humanos-, se usan tales calificaciones. Y parece que las gentes aceptan que tales calificaciones tienen sentido, y ciertamente un sentido estimable, un sentido justificado; el hecho de que esas connotaciones no constituyen simplemente palabras, antes bien factores operantes de un modo real y efectivo en muchos asuntos humanos.

Ciertamente que el descubrimiento de ese "factum", el hecho del razonamiento en los asuntos humanos, es muy añejo, cual se ha expuesto en la primera parte del presente trabajo, pues ese descubrimiento aparece ya en una de las acepciones de la palabra dialéctica en la filosofía de la Antigüedad clásica, incluso en los sofistas, y aun antes en algunos de los pensadores eléatas y pitagóricos -aunque en éstos sólo de un modo marginal y muy leve.

Cierto también que al producirse el hallazgo de ese hecho, la toma de conciencia de ese factum, no se le volvió la espalda por el pensamiento filosófico. Por el contrario, la presencia consciente de ese hecho suscitó las obras que han sido aludidas en la primera parte del presente estudio. Y reconozcamos, además, que en esas obras se señalaron dimensiones y características muy importantes, y de modo muy certero, de ese hecho. Tanto, que parece no sólo discreto, antes bien, obligado, tomar en cuenta y aprovechar ese legado de la dialéctica, tópica y retórica antiguas. Como parece también imperativo aprovechar las varias y muy fecundas inspiraciones que nos ofrecen los autores contemporáneos a los que antes hube de referirme. Hacer todo eso está muy bien;' debemos hacerlo. Pero hay que esforzarnos por hacer algo más: sin olvidar lo que del pretérito y del presente hemos aprendido, tal vez sería conveniente que nos esforzásemos en empezar de nuevo a fondo el análisis de este tema.

Al fin $y$ al cabo, la forma típicamente característica de desarrollo de 
la filosofía es la de la superación radical, es decir, el comenzar cada vez de nuevo, desde los mismos cimientos, para intentar otra construcción, aunque en ésta se aproveche mucho de las conquistas y lecciones anteriores.

Hay ciencias -observa Scheler-, como por ejemplo la botánica y la zoología, las cuales se desenvuelven principalmente - aunque no de modo exclusivo- por el camino de la acumulación progresiva, es decir, añadiendo sucesivamente nuevos descubrimientos a los logrados antes, en una serie que aumenta cuantitativamente.

Hay otros campos culturales - como sucede, por ejemplo, en el despliegue sucesivo de las posibilidades de un estilo artístico- en las que el tipo principal de desenvolvimiento es el de la maduración orgánica, o desarrollo cada vez más complejo y mejor logrado de las funciones insertas como trayectoria iniciada (pero todavía no cumplidas) o apuntadas germinalmente en anteriores productos.

En cambio, el modo típico de la filosofía -y también de algunas ciencias-, la superación radical consiste en proceder cada vez a la rigorosa revisión de los supuestos mentales de que se habia partido antes, para remediar las insuficiencias o las fallas que éstos mostraron; proceder a re-descubrir el dato radical, el genuino punto de partida; el proceder además a una nueva delimitación del objeto de trabajo y a un nuevo contraste de los métodos.

En suma, lo que propongo es lo siguiente: esforzarse en planear una nueva "crítica de la razón", pero esta vez ni de la "razón pura teorética", ni de la "razón pura práctica", sino de la "razón de lo razonable" de la "razón de los asuntos humanos", de la razón de la "razón deliberante o argumentativa".

Mucho ha realizado al servicio de ese propósito Chaim Perelman; pues en sus trabajos hay logros muy estimables de largo alcance. Reconozco esto sinceramente con elogio y con admiración, independientemente de algunas discrepancias - por ejemplo, en lo que respecta al "auditorio o público"que no es oportuno discutir en este breve artículo, y de las que me ocuparé en otros trabajos míos que me propongo escribir.

En otras varias publicaciones anteriores, 48 he esbozado algunas de las dimensiones y características del logos de la. vida humana o "lógica de lo razonable". Recordaré aquí someramente algunas de esas características: $A$ ) Como quiera que el hombre opera siempre en un mundo concreto, en una circunstancia real, limitada, y caracterizada por rasgos particulares, la acción del hombre y el logos que dirige a ésta, se hallan limitados o circunscritos por la realidad concreta del contorno y, especialmente, por la realidad del mundo social particular, respecto de cuyos problemas se delibera, se argumenta y se trata de hallar la solución prudente o razonable. B) El hombre

48 Véanse obras citadas en la nota 39. 
siente necesidades y afronta problemas cuya solución no le es ofrecida automáticamente por mecanismos de la naturaleza; lo cual le plantea al hombre el tener él que hallar por su propia cuenta una solución. Para ello, busca con su imaginación algo que aún no existe hoy, o que, aunque exista, no lo tiene ahí a la mano, pero que si existiese o estuviese ahi, satisfaria la necesidad que siente o el problema que afronta. Cuando su mente se satisface con algo imaginado que todavía no existe, o que no está al alcance de la mano, entonces se propone como fin la consecución de ese algo. Una vez establecido el fin de la acción, el hombre se dedica a buscar los medios (causas adecuadas) para lograr aquel fin, esto es, para producir aquel resultado apetecido. C) En la búsqueda imaginativa de aquello que pueda resolver un problema práctico, intervienen múltiples valoraciones, valoraciones concretas, es decir, referidas a una determinada situación, y, por lo tanto; en ellas se toman en cuenta las posibilidades y las limitaciones reales. D) Entre esas varias valoraciones - las más de las veces combinadas entre si- figuran las siguientes: $x$ ) sobre la adecuación del fin para satisfacer la necesidad o resolver el problema; 2) sobre la justificación de ese fin, desde varios puntos de vista: moral, de justicia, de decencia, de utilidad, de conveniencia, de adecuación, etc.; 3) sobre la adecuación entre los fines y una determinada realidad humana; 4) sobre la adecuación entre los fines y medios, en cuanto a la conveniencia de los medios para los fines; 5) sobre la corrección ética de los medios; y 6) sobre la eficacia de los medios. E) Todos esos procesos de deliberación, ponderación, enjuiciamiento, se hallan $\longrightarrow$ deben hallarse - orientados por las enseñanzas de la experiencia vital e histórica, esto es, individual y social; y se desenvuelven, o deben desenvolverse, de acuerdo con las lecciones sacadas de tales experiencias.

Conviene ahora recordar algunas observaciones hechas ya por varios autores; y no sólo recordarlas, sino además tratar de afinarlas, y de comprender mejor los fundamentos de ellas.

Con razón se ha observado desde Aristóteles hasta Perelman - pasando por todas las etapas intermedias- que en asuntos dirigidos por la tópica y en los concernientes a la prudencia, en los que intervienen la deliberación y la argumentación, no se puede jamás hallar una tesis absolutamente válida, la cual excluya o repudie como inválida cualquiera otra tesis que discrepe de aquélla. En esos asuntos no se trata de la verdad, así pura y simplemente, y de lo opuesto a ella, la falsedad. Porque no se trata de averiguar la esencia o la realidad de una idea o de una cosa. Por el contrario, se trata de encontrar para un determinado problema práctico de conducta humana, para una controversia de opiniones, o para un conflicto de intereses, la solución relativamente mejor, la más adecuada, la más viable, la más satisfactoria. Pero ninguno de tales calificativos ni de otros similares puede ser proferido en términos absolutos, tajantes, que impliquen la ex- 
presión del único acierto, el cual excluya necesariamente como rechazable en términos absolutos cualquier otro.

Para resolver un problema humano, un conflicto de opiniones, una controversia de intereses, etc., es posible intentar la formulación de diferentes soluciones. Probablemente, seguramente, no todas esas soluciones propuestas tendrán el mismo valor. Aparte de que algunas justificadamente deberán quedar desechadas, es muy posible, incluso muy probable -es lo que sucede las más de las veces- que queden después de la eliminación de las rechazables, varias soluciones posibles. Muy probablemente entre esas varias soluciones posibles habrá unas mejores que otras; y entre las unas, es decir, las primeras, o sea las que parecen mejores, cabrá otorgar cierta relativa preferencia a una determinada. Todo ello por razonamientos fundados, justificados, pero no con dimensión exacta, tajante, con validez absoluta - la cual validez absoluta implique la condenación de cualquiera otra tesis posiblemente también aceptable. Como se ha señalado muchas veces - desde Aristóteles hasta Perelman- el conocimiento teórico, sistemático - propiamente el apodíctico, racional, y en alguna medida el de las ciencias de hechos que operan mediante la inducción-, aspira a la verdad; y la verdad es una, y cualquier otra proposición que discrepe de ella es falsa, totalmente falsa, por completo rechazable.

En efecto: $2+2$ suman 4. Ésta es la verdad válida. La única verdad válida. Si alguien dice que $2+2$ suman 3 y medio, esto es rotundamente falso. Como es igualmente falso el decir que $2+2$ suman 4 y cuarto.

Ahora bien, imagínese el lector un problema jurídico o un problema político. Veamos primero un ejemplo en el campo del Derecho: supongamos que ha tenido lugar un proceso penal, que se llevó a cabo el juicio, y que el tribunal condenó al acusado a una pena de cuatro años y cinco meses de prisión. Examinamos el proceso en todo su desarrollo, en todos sus detalles, en todas sus etapas y, especialmente el fallo, a la luz del Derecho positivo vigente; $y$ después de tal análisis nos sentimos satisfechos, creemos sinceramente que el fallo dictado por el tribunal se acomoda a las reglas jurídicas en vigor, y que el juicio fue sustanciado impecablemente de acuerdo con los preceptos procesales. Imaginemos además que examinamos el mismo caso a la luz de unos criterios de axiología jurídica, y que, desde el punto de vista de éstos, el fallo nos parece igualmente correcto. Pero ahora formulo la siguiente pregunta: ¿y si el tribunal hubiese condenado al acusado a una pena de prisión por cuatro años y cuatro meses y medio, reputaríamos la sentencia contraria a Derecho u opuesta a la justicia? ¿Y si el tribunal lo hubiera condenado a cuatro años y cinco meses y medio de prisión, rechazariamos por contraria a Derecho o por injusta esa sentencia? Este ejemplo aclara elocuentemente que en materia jurídica - lo mismo que en problemas políticos, domésticos, etc. - no hay "una". verdad, y que cualquier 
otro intento de aserto haya de ser necesariamente falso. No se trata de verdad y falsedad. Lo que hay, lo único que puede haber, son soluciones relativamente mejores que otras, más prudentes que otras, más adecuadas que otras, más justas que otras.

Pensemos además que en la inmensa mayoría de las controversias jurídicas - así como de las discusiones políticas y de las que versan sobre problemas económicos, o sobre otros tipos de relaciones interhumanas- no hay "una" verdad que salte a primera vista. En primer lugar, hay que rectificar el empleo de la palabra "verdad", porque tal vocablo es por entero inadecuado en relación con esos problemas. Tales problemas no son jamás problemas de verdad o de falsedad: son problemas que deben ser juzgados a la luz de otros valores: morales, políticos, jurídicos, de decoro, de conveniencia, de utilidad, etc. $\mathrm{Y}$ en las áreas cubiertas o regidas por tales valores no hay "exactitud", no hay "univocidad", no hay divisiones tajantes. Si los términos de una controversia jurídica apareciesen a primera vista, o pudiesen ser demostrados mediante deducciones, con la evidencia que caracteriza al pensamiento matemático, no habría pleitos. Sólo un demente podría promover un pleito con la pretensión de que se declarase que $2+2$ suman 5 .

Lo mismo acontece respecto de los problemas políticos. En los Estados civilizados, no habría la necesidad de que existiese un parlamento en el que se deliberase, en el que se discutiera en busca de la solución mejor; y en los Estados dictatoriales, el mandamás no necesitaría consejeros. A este respecto, recuerdo que el iusfilósofo francés Michel Villey 49 escribía, precisamente en $196 \mathrm{r}$, respecto del Derecho natural -pero lo mismo cabría decir en lo que atañe a otros muchos asuntos relativos a la conducta humana: uno de los axiomas capitales del Derecho natural... es que el Derecho no puede jamás adquirir la forma deductiva ni la necesidad de una ciencia; in negotiis humanis non potest haberi demonstrativa probatio; se trata de un asunto de la prudencia, de esa investigación flexible que se ejerce en el reino de lo contingente. La prudencia es la virtud propia del legislador, del jurista (que los romanos llamaban jurisprudente). No, la inteligencia por sí sola, observando los hechos naturales, no puede llegar a la solución. ¿Cuál puede ser la solución justa del problema de Argelia? ¡Cuántos argumentos por una parte y por la otra! ¿Qué lejos estoy yo de tener una respuesta cierta!... ¿Cuál es la tasa del precio justo? Los clásicos jamás pensaron que "la naturaleza" suministrara la cifra.

Yo querría añadir otra observación que contribuye a producir alguna claridad - tal vez tan sólo un poquito de claridad, pero alguna, en fin de cuentas- sobre esa característica en el tratamiento y la solución de los asuntos humanos, consistente en que se puede dar un más o un menos, un mejor o un peor, un punto de vista relativo y flexible. Es característi-

49 Véase Michel Villey, Abrégé du droit naturel classique, Sirey, Paris, 1961. 
ca de la vida humana y de las obras en ella producidas, el tener un ser susceptible de gradaciones jerárquicas. Esas gradaciones jerárquicas tienen dos fuentes o dimensiones, a saber: a) el rango de los diversos valores; y b) el grado de mayor o menor realización de cada uno de los valores. Esto nos pone certeramente sobre la pista de las relaciones de la estructura de la existencia humana con la estructura de lo estimativo. La vida humana, y sus actos y sus obras, tienen - a diferencia del mundo de las ideas puras y del mundo de la naturaleza - perspectivas de rango y jerarquía. Mientras que la naturaleza pura, como concatenación de fenómenos, desconoce toda jerarquía, las realidades humanas, en cambio, presentan la doble dimensión jerárquica a la que acabo de referirme. Esto trae consigo que haya grados de realización en las tareas humanas; que haya arte que sea más arte que otro, amores que sean más amores que otros, filosofía que sea más filosofía que otra, soluciones a problemas que sean mejores que otras soluciones posibles (aunque éstas no siempre necesariamente malas ni rechazables).

Por otra parte, hay otro punto que debemos tener en cuenta: el de la esencial historicidad de la vida humana. Reconocer que la existencia del hombre es esencialmente histórica no trae aparejada como consecuencia necesaria negar la dimensión objetiva de los valores. Yo me inclino a la tesis de que la esencia de los valores consiste en que ellos son ideas a priori, objetivas. Sin embargo, tenemos que preguntarnos cómo sea posible articular las exigencias de esas ideas, dotadas de validez necesaria, con las demandas múltiples, varias y cambiantes de cada individuo particular y de cada realidad social histórica. Pero adviértase que, propiamente, no se trata de articular las ideas de valor con los hechos históricos, sino que se trata de otra cosa. Se trata en lo que se refiere a la realización de las exigencias normativas ideales derivadas de los valores pertinentes, de armonizar el cumplimiento de esas exigencias con las circunstancias y realidades humanas concretas, cada una de ellas particular. Es decir, lo que hay que concordar no son valores puros y hechos humanos individuales e históricos, sino que lo que hay que hermanar es la puesta en práctica de las exigencias de los valores con las características concretas de las situaciones particulares, de los problemas singulares. Se trata, en definitiva, de un problema de realización de las orientaciones, criterios, o guías que manan de los valores. La diversidad, el cambio, la flexibilidad, la relatividad, no se predican de los valores, sino de la realización de las exigencias o directrices prácticas de éstos en la vida humana. Y la vida humana es esencialmente histórica, la vida humana es la conjugación del sujeto con los objetos que forman el contorno; y la vida humana social es la textura formada por determinadas relaciones entre múltiples vidas humanas en unos especiales aspectos. Pues bien, los dos ingredientes que forman las vidas humanas - sujetos concretos y circunstancias- están sometidos a la diversidad y al cambio. 
Además mi vida, nuestra vida, la vida de cada quien, la vida de un conjunto de seres humanos, en su realidad de cada momento, la vamos construyendo nosotros con los materiales de que disponemos, tejiéndola en selección de algunas de las posibilidades que nos depara la circunstancia concreta.

Parece oportuno recordar en este momento mi tesis de que la objetividad de los valores no es una objetividad abstracta, sino una objetividad intravital; es decir, que, aun cuando los valores son objetivos, se dan, como todos los demás objetos, en nuestra vida, como componentes de ella, y con sentido para ella. Que puedan tener o no un sentido más allá de ella o fuera de ella, es un tema inabordable. Yo me limitaria a decir que lo único que podemos afirmar es que Dios piensa esos valores como válidos y con sentido para la vida humana. Más allá de esta afirmación, careceríamos de todo fundamento para cualquier otro aserto. Nótese que lo que acabo de exponer no contiene ninguna negativa, no niega que pueda haber un sentido trascendente de los valores: se limita a reconocer que nosotros podemos hablar tan sólo del sentido de los valores para nuestra vida - reconociendo que en ella y para ella tienen una dimensión de irrefragable objetividad.

Las consideraciones que anteceden pueden contribuir en alguna medida a explicar los claroscuros y las dimensiones debatibles en las funciones argumentativas, en el mundo de los problemas prácticos de la vida humana.50

Luis RecasÉns Siches

50 Véase Luis Recaséns Siches, Tratado general de filośofía del Derecho, segunda edición. Editorial Porrúa, México, 1961, págs. 58-83; $4^{61-78 .}$ 